\title{
LETTER
}

\section{Circulating microRNAs: promising breast cancer biomarkers}

\author{
Helen M Heneghan, Nicola Miller* and Michael J Kerin \\ See related research by Roth et al., http://breast-cancer-research.com/content/12/6/R90 and related letter by Roth et al., \\ http://breast-cancer-research.com/content/13/1/403
}

We read with interest the recent article by Roth and colleagues [1] reporting the findings of altered tumorspecific microRNAs (miRNAs) in sera of breast cancer patients. This report further substantiates emerging data suggesting that blood-based miRNAs have immense potential as novel non-invasive cancer biomarkers. However, we have several concerns regarding the authors' study.

Roth and colleagues claim this article to be the first evidence that circulating miRNAs have potential as breast cancer biomarkers, yet refer to previous reports of similar findings $[2,3]$. This aside, other claims in the study are unsubstantiated. Firstly, the finding that total RNA levels were significantly higher in M0 patients compared to controls and M1 breast cancer patients most likely reflects the quality of RNA extraction techniques and is not clinically relevant. We have previously demonstrated that total RNA levels differ significantly depending on the RNA isolation method and starting blood medium [2]. The authors have not adequately discussed their finding that patients with metastatic disease had significantly lower total RNA levels compared to M0 patients; if their claim that total RNA concentration indicated tumour progression held truth, then one would expect a sequential increase in total RNA concentration from controls, to $\mathrm{M} 0$ and $\mathrm{M} 1$ patients.

The four candidate miRNAs (miR-10b, miR-34a, $m i R-141$, and $m i R-155)$ selected by Roth and colleagues for analysis is contentious. Evidence demonstrating consistent differential expression of this miRNA panel in breast tumours, and functionality in breast tumour genesis and progression, is lacking. Given that currently 1,212 mature human miRNAs have been identified (miRBase, release 16 September 2010 [4]), and others

\footnotetext{
*Correspondence: nicola.miller@nuigalway.ie

Department of Surgery, National University of Ireland, Galway, Clinical Science Institute, Costello Road, Galway, Ireland
}

strongly associated with breast cancer, there are more appropriate miRNAs worthy of consideration as breast cancer biomarkers.

Another concerning issue is the time-point at which serum samples were obtained from patients. Our group has previously demonstrated that circulating miRNAs that are elevated in breast cancer patients when the tumour is in situ (miR-195 and let-7a) decrease to basal levels by 2 weeks post-tumour resection. Whilst the halflife of tumour-associated miRNAs in blood is undefined, ours and other studies would suggest that it is less than 14 days [5]. The authors' samples were obtained from M0 patients as late as 4 weeks post-operatively, at which time there would have been no disease, or at most microscopic foci, remaining. As the authors' primary aim was to evaluate the feasibility of using circulating miRNAs for detection and staging of breast cancer, it would have been prudent to obtain blood samples pre-operatively.

We do believe that blood-based miRNA analysis has imminent clinical utility as tumour markers. However, if this concept is to translate readily from bench to bedside, then supporting data demonstrating feasibility and validity of this novel approach must stem from carefully planned and well-designed studies. If the current momentum in miRNA translational research can be maintained, then an era of non-invasive rapid diagnostics and individualized care for breast cancer patients is rapidly forthcoming.

\section{Abbreviations \\ miRNA, microRNA.}

\section{Competing interests}

The authors have applied for a patent regarding the detection and quantification of miRNAs in the circulation and the use of circulating miRNAs as biomarkers for cancer. This has not yet been granted.

\section{Acknowledgments}

Funding for this work was provided by a Health Research Board Fellowship Award (to HMH), and the National Breast Cancer Research Institute (NBCRI), Ireland.

Published: 4 February 2011 


\section{References}

1. Roth C, Rack B, Muller V, Janni W, Pantel K, Schwarzenbach H: Circulating microRNAs as blood-based markers for patients with primary and metastatic breast cancer. Breast Cancer Res 2010, 12:R90.

2. Heneghan HM, Miller N, Lowery AJ, Sweeney KJ, Newell J, Kerin MJ: Circulating microRNAs as novel minimally invasive biomarkers for breast cancer. Ann Surg 2010, 251:499-505.

3. Zhu W, Qin W, Atasoy U, Sauter ER: Circulating microRNAs in breast cancer and healthy subjects. BMC Res Notes 2009, 2:89.

4. miRBase [http://www. mirbase.org/]
5. Mitchell PS, Parkin RK, Kroh EM, Fritz BR, Wyman SK, Pogosova-Agadjanyan EL, Peterson A, Noteboom J, O'Briant KC, Allen A, Lin DW, Urban N, Drescher CW, Knudsen BS, Stirewalt DL, Gentleman R, Vessella RL, Nelson PS, Martin DB, Tewari M: Circulating microRNAs as stable blood-based markers for cancer detection. Proc Natl Acad SciU S A 2008, 105:10513-10518.

doi:10.1186/bcr2798

Cite this article as: Heneghan HM, et al:: Circulating microRNAs: promising breast cancer biomarkers. Breast Cancer Research 2011, 13:402. 